\title{
Design and Finite Element Analysis of All- Terrain Vehicle Roll Cage
}

\author{
${ }^{1}$ Prashant D Chaudhari, ${ }^{2}$ Gaurav S Gajare \\ ${ }^{1,2}$ Department of Mechanical Engineering, Dr. Vithhalrao Vikhe Patil College of Engineering, \\ Ahmednagar, Maharashtra, India \\ 1'prashantchaudhari4296@gmail.com, ${ }^{2}$ gauravgajare84@gmail.com
}

\begin{abstract}
The paper emphasizes on designing a high performance All-Terrain Vehicle (ATV). We started the designing of 3D model of vehicle using CATIA V5 software. With considering, the critical parameters such as overall weight, safety, high strength, and ergonomics, the roll cage of all-terrain vehicle is designed and then its static analysis is carried out. The Roll cage plays a major role which provides safety to the driver and also it is a main building block of ATV. In this research paper, the roll cage is designed by considering all the constraints provided by SAE (Society of Automotive Engineers). The finite element analysis was done using ANSYS 15.0. Various impacts that the roll cage can undergo are studied. From the optimum design with considering the factor of safety in the account, the roll cage was designed with superior weight to strength ratio. The results obtained after the analysis stated the designed to be safe and sound.
\end{abstract}

Keywords - All Terrain Vehicle, Ergonomics, FEA, Roll Cage, SAE, Safety.

\section{INTRODUCTION}

The roll cage is a basic building block of an ATV. It protects the driver and safeguards all the other systems inside. It also supports all the systems such as the steering system, suspension system, transmission system, etc. The objective of this paper is to design a lightweight and high strength roll cage. The cockpit dimensions are assumed according to average driver size. And Engine compartment dimensions are taken according to engine and transmission dimensions. Using this assumption no. of designs were made in CATIA V5 so that optimum strength to weight ratio can be obtained. Final selection of design was done by using ANSYS 15.0 Software. It is important to consider all the possible circumstances which will lead to failure. The aim of this paper is to calculate and study the stress-strain behavior of Roll cage at every possible static loading condition. The performance of the vehicle during the race depends upon the design of safe and lightweight roll cage. Driver spends maximum time during the into the cockpit hence it becomes more important to make the cockpit more friendly and comfortable for the driver handling.

\subsection{Design Specifications}

The roll cage is designed considering all the rules in SAE BAJA rule book 2018 [1]. Clearance of 3 inches is to be maintained between driver and roll cage members. The circular tube is used for roll cage having 1 inch OD \& 2 $\mathrm{mm}$ thickness. The material used for the tube is AISI 4130 its selection is discussed in the following topic.

\subsection{Material Selection}

One of the important design consideration that increases the safety, reliability and performance in any automobile design is the material selection. As per the rule book constraint, there should be at least $0.18 \%$ of carbon content in metal according to BAJA SAE INDIA rulebook [1]. Considering strength to weight ratio of material we selected AISI 4130 (Chromoly) material for our design. One more property of AISI 4130 while selecting material was its corrosion resistance. Chromoly is an alloy steel of chromium and molybdenum. Molybdenum helps in increasing the strength of the material. Following is the comparison of AISI 1080 \& AISI 4130 material considered.

\begin{tabular}{|c|c|c|}
\hline Material & AISI 1080 & AISI 4130 \\
\hline Density $\left(\mathrm{kg} / \mathrm{m}^{3}\right)$ & 7870 & 7850 \\
\hline $\begin{array}{c}\text { Yield Strength } \\
\text { (MPa) }\end{array}$ & 370 & 460 \\
\hline $\begin{array}{c}\text { Tensile Strength } \\
(\mathrm{MPa})\end{array}$ & 440 & 731 \\
\hline
\end{tabular}

Table 1: Material Comparison

\section{METHODOLOGY}

Designing of ATV Roll cage is a creative work. Where we have to follow all the constraints given in BAJA SAE INDIA rulebook. Following those constraints we first made a rough sketch on paper and dimensions were taken according to the average size of a human being. Then for 
modelling, we used CATIA V5 software. While modelling weight of Roll cage was considered as it plays a major role in the performance of an ATV. For minimizing the weight of a roll cage thickness of pipe was optimized to $2 \mathrm{~mm}$ as it is provided to be greater than $1.6 \mathrm{~mm}$ according to $\mathrm{SAE}$ Rulebook [1]. Even though we used the thickness of $2 \mathrm{~mm}$, the strength of a roll cage was not compromised as we used better strength to weight ratio material AISI 4130 (chromemoly). Our model was further analyzed in ANSYS 15.0 software. By following all the above constraints we finally modelled our design which is shown in Fig. 1(a,b,c).

\begin{tabular}{|c|c|}
\hline Attributes & Values \\
\hline Length & $1850 \mathrm{~mm}$ \\
\hline Width & $889 \mathrm{~mm}$ \\
\hline Height & $1194 \mathrm{~mm}$ \\
\hline Weight & $30 \mathrm{~kg}$ \\
\hline Weight (with driver) & $210 \mathrm{~kg}$ \\
\hline
\end{tabular}

Table 2. Basic dimensions of following Roll cage

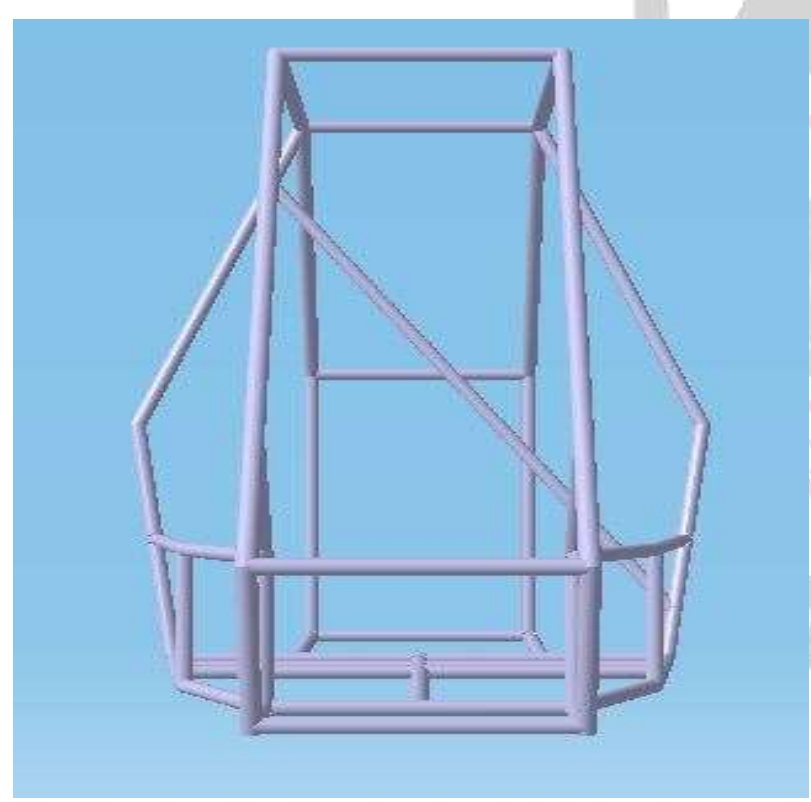

Figure 1(a): Front View of Roll Cage

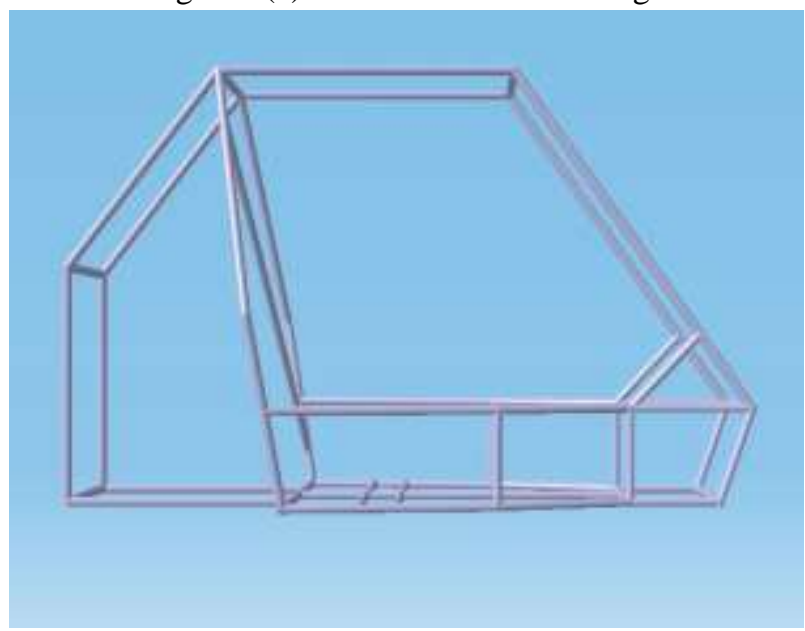

Figure 1(b): Side View of Roll Cage

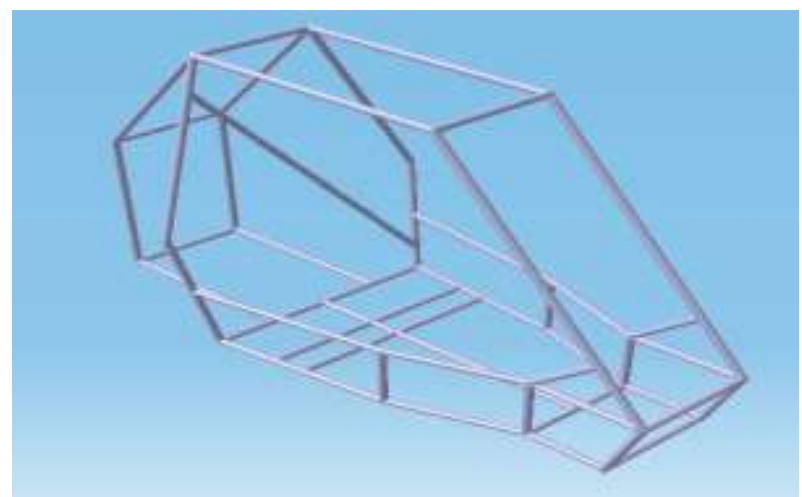

Figure 1(c): Isometric View of Roll Cage

\section{FINITE ELEMENT ANALYSIS (FEA)}

Analysis of a roll cage can be performed on different software. Out of which more favorable and user-friendly is ANSYS. We have used ANSYS 15.0 for our roll cage analysis. While performing FEA weight of ATV with the driver was considered to be $210 \mathrm{~kg}$. And other following assumptions were made.

1. Cross section of a roll cage is uniform.

2. The roll cage is stationary

3. Time of impact is considered to be 0.2 seconds.

4. The material is Homogeneous.

5. Boundary conditions were applied to suspension mounting points (constrained).

6. Meshing:
A. Mesh Size - $3.5 \mathrm{~mm}$
B. Element Type - Triangles \& Quadrilaterals

3.1 Front Impact Analysis

\section{A. Impact force calculation}

During front impact analysis roll cage is considered to be stationary. And forces are applied on the front face of the roll cage.

Force applied is calculated as follows:

Mass $=210 \mathrm{~kg}$

Max. Velocity (Initial velocity) $=60 \mathrm{~km} / \mathrm{hr}$

$$
=16.67 \mathrm{~m} / \mathrm{sec}
$$

Time of Impact $=0.2 \mathrm{sec}$

Final Velocity $=0 \mathrm{~m} / \mathrm{sec}$.

Force $=$ mass $\mathrm{x}$ (initial velocity - final velocity $) /$ Time of impact

$F=210 \times(16.67-0) / 0.2$

$\mathrm{F}=17503.5 \mathrm{~N}$

B. Front impact Ansys 15.0 images 


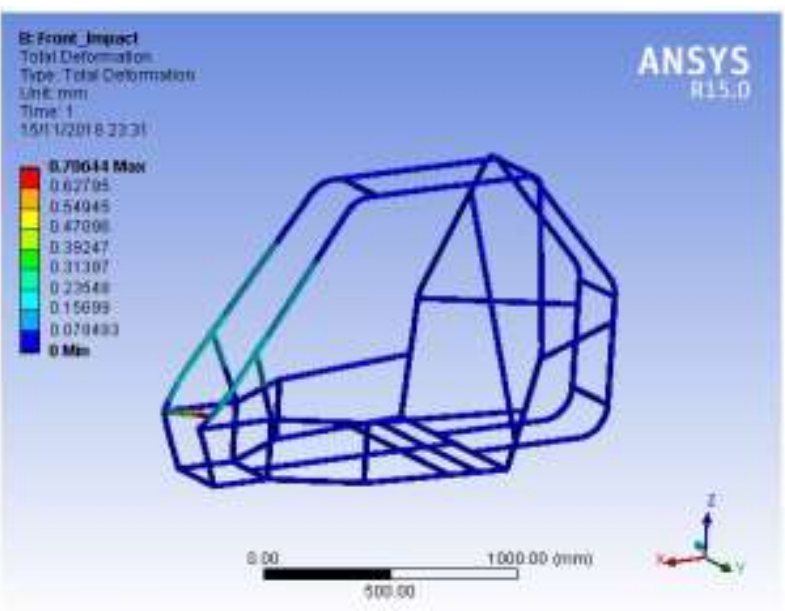

Figure 2: Total Deformation in Front Impact

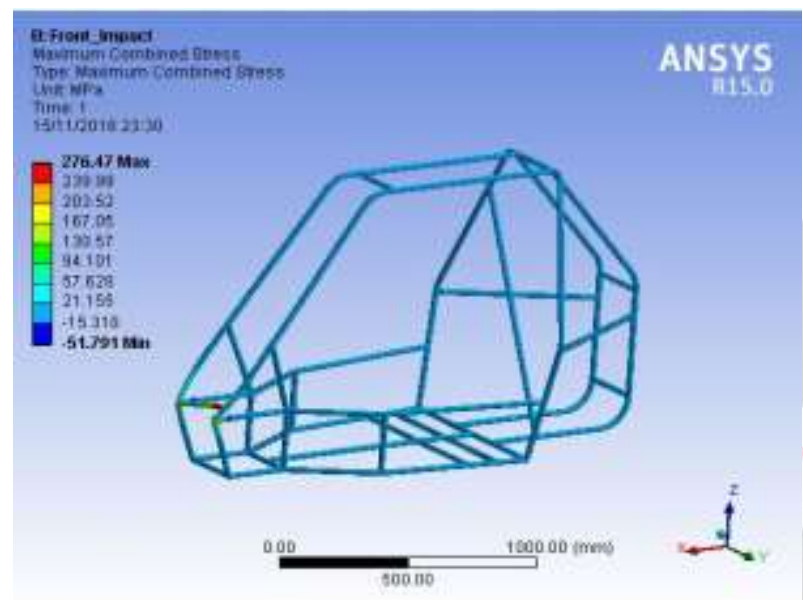

Figure 3: Max. Stress in Front Impact

\section{The factor of Safety (FOS)}

The factor of the safety of roll cage should be greater than 1.5. From front impact analysis maximum stress obtained is 276.47 MPa. So FOS can be calculated as follows.

FOS $=$ Maximum stress/ Allowable stress

$$
\begin{aligned}
& =460 / 276.47 \\
& =1.66
\end{aligned}
$$

Here FOS obtained for front impact is 1.66 which is greater than 1.5. So we can conclude that our design is safe in front impact analysis.

\subsection{Rear Impact Analysis}

\section{A. Impact force calculation}

The similar to front impact analysis roll cage is considered to be stationary. And forces are applied on a rear part of the roll cage.

Force applied is calculated as follows:

Mass $=210 \mathrm{~kg}$

Max. Velocity (Initial velocity) $=60 \mathrm{~km} / \mathrm{hr}$

$$
=16.67 \mathrm{~m} / \mathrm{sec}
$$

Time of Impact $=0.2 \mathrm{sec}$
Final Velocity $=0 \mathrm{~m} / \mathrm{sec}$.

Force $=$ mass $\mathrm{x}($ initial velocity - final velocity $) /$ Time of impact

$\mathrm{F}=210 \times(16.67-0) / 0.2$
$\mathrm{~F}=17503.5 \mathrm{~N}$

B. Rear impact Ansys 15.0 images

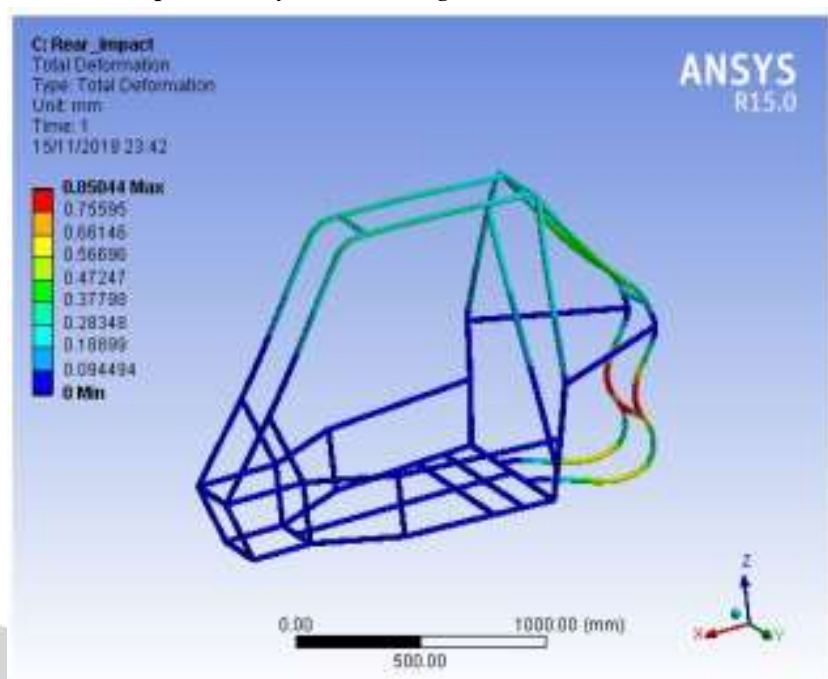

Figure 4: Total Deformation in Rear Impact

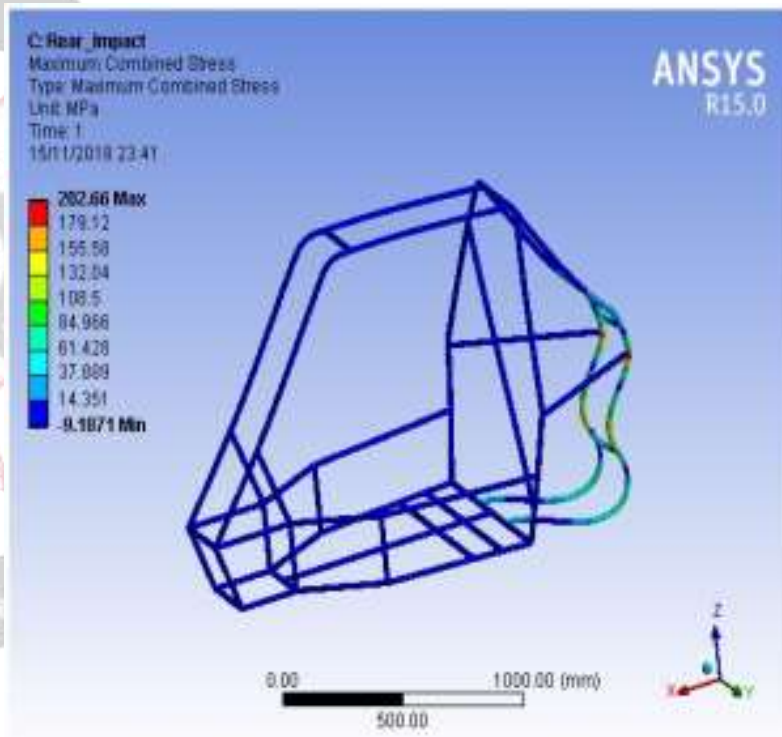

Figure 5: Max. Stress in Rear Impact

\section{The factor of Safety (FOS)}

The factor of the safety of roll cage should be greater than 1.5. From rear impact analysis maximum stress obtained is 202.66 MPa. So FOS can be calculated as follows.

FOS $=$ Maximum stress/ Allowable stress

$$
\begin{aligned}
& =460 / 202.66 \\
& =2.26
\end{aligned}
$$

Here FOS obtained for rear impact is 2.26 which is greater than 1.5. So we can conclude that our design is safe in rear impact analysis.

3.3 Side Impact Analysis

A. Impact force calculation 
In Side Impact Analysis side forces are considered to be $\mathrm{g}$-force. Forces are applied on the side impact members and suspension mountings are constrained while analysis.

$\mathrm{G}$-force is calculated as follows

Mass $=210 \mathrm{~kg}$

Gravitational force $=10 \mathrm{~m} / \mathrm{s}^{2}$

Side Impact Forces $=3 \times$ gravitational force $\mathrm{x}$ mass

$$
\begin{aligned}
& =3 \times 10 \times 210 \\
& =6300 \mathrm{~N}
\end{aligned}
$$

\section{B. Rear impact Ansys 15.0 images}

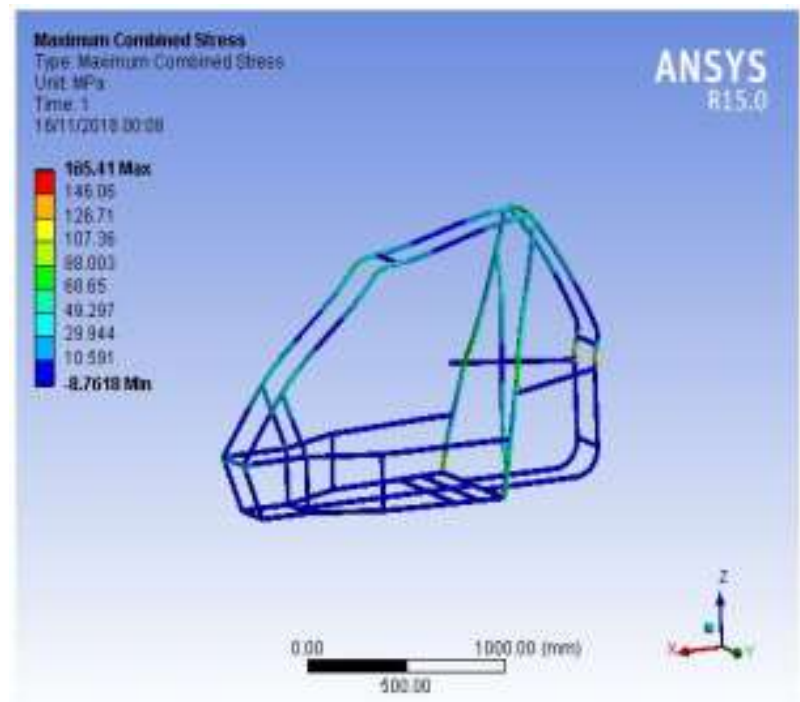

Figure 6: Total deformation in side impact

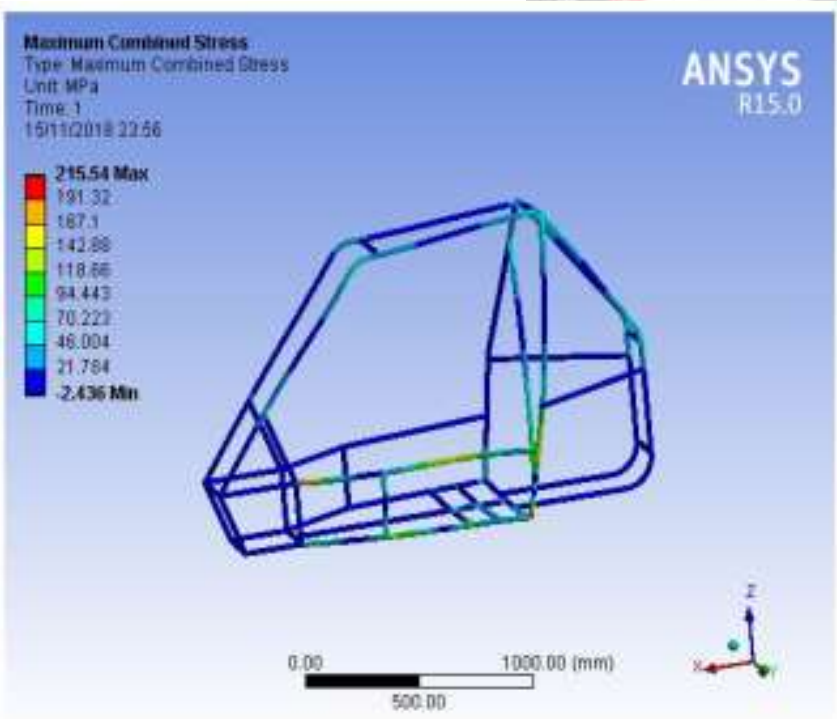

Figure 7: Max. Stress in Side Impact

\section{The factor of Safety (FOS)}

The factor of safety of roll cage should be greater than 1.5. From side impact analysis maximum stress obtained is 215.54 MPa. So FOS can be calculated as follows.

FOS $=$ Maximum stress/ Allowable stress

$$
=460 / 215.54
$$

$$
=2.13
$$

Here FOS obtained for side impact is 2.13 which is greater than 1.5. So we can conclude that our design is safe inside impact analysis.

\subsection{Front Roll Over Analysis}

\section{A. Impact force calculations}

During Front Rollover Analysis impact force location is considered first at roll cage members in contact. Here also g-force is considered for application. We have applied the calculated g-force to the members which are first coming in contact with the road surface. Forces are applied normal to the curved surface of the roll cage. And the suspension mount is constrained as in all the above cases.

G-force is calculated as follows

Mass $=210 \mathrm{~kg}$

Gravitational force $=10 \mathrm{~m} / \mathrm{s}^{2}$

Front roll over force $=3 \mathrm{x}$ gravitational force $\mathrm{x}$ mass

Front roll over force $=3 \times 10 \times 210$

$$
=6300 \mathrm{~N}
$$

\section{B. Front roll over Ansys 15.0 images}

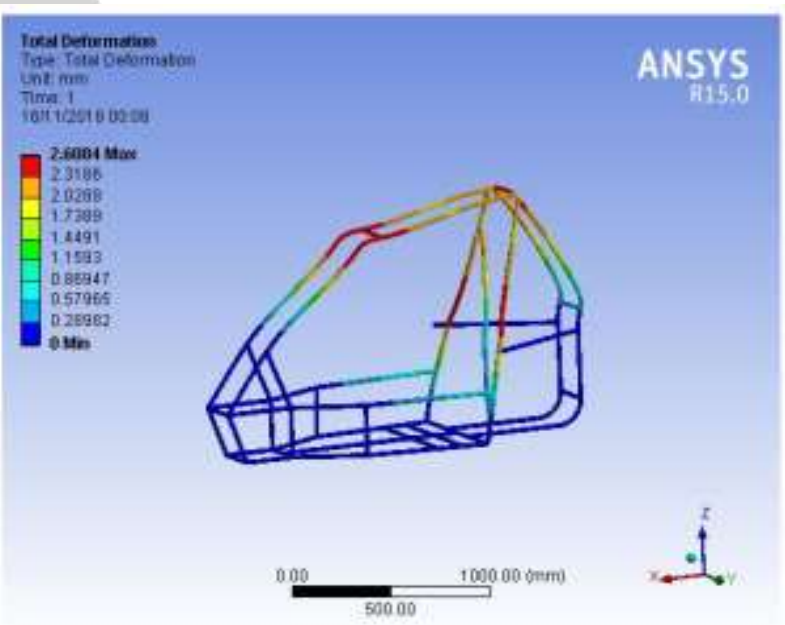

Figure 8: Total Deformation in Front rollover

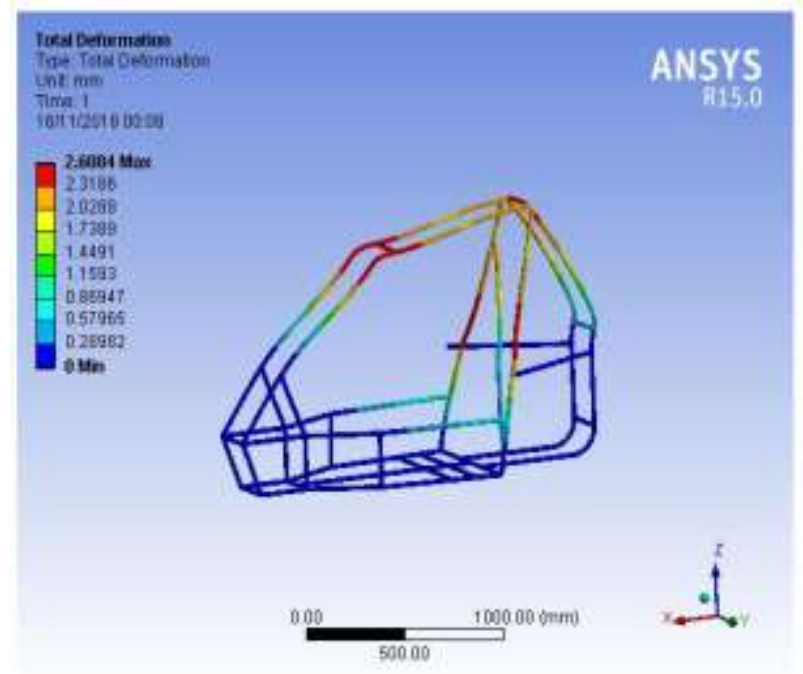

Figure 9: Max. Stress in Front rollover 


\section{The factor of Safety (FOS)}

The factor of the safety of roll cage should be greater than 1.5. Front rollover analysis maximum stress obtained is 165.41 MPa. So FOS can be calculated as follows.

FOS = Maximum stress/ Allowable stress

$$
\begin{aligned}
& =460 / 165.41 \\
& =2.78
\end{aligned}
$$

Here FOS obtained for front roll over is 2.78 which is greater than 1.5. So we can conclude that our design is safe in a front roll over analysis.

\subsection{Rear Rollover Analysis}

\section{A. Impact force calculations}

During Rear Rollover Analysis impact force location is considered first at roll cage members in contact. Here also g-force is considered for application. We have applied the calculated $g$-force to the members which are first coming in contact with the road surface. Forces are applied normal to the curved surface of the roll cage. And the suspension mount is constrained as in all the above cases.

G-force is calculated as follows

Mass $=210 \mathrm{~kg}$

Gravitational force $=10 \mathrm{~m} / \mathrm{s}^{2}$

Front roll over force $=3 \mathrm{x}$ gravitational force $\mathrm{x}$ mass

Front roll over force $=3 \times 10 \times 210$

$$
=6300 \mathrm{~N}
$$

\section{B. Rear roll over Ansys 15.0 images}

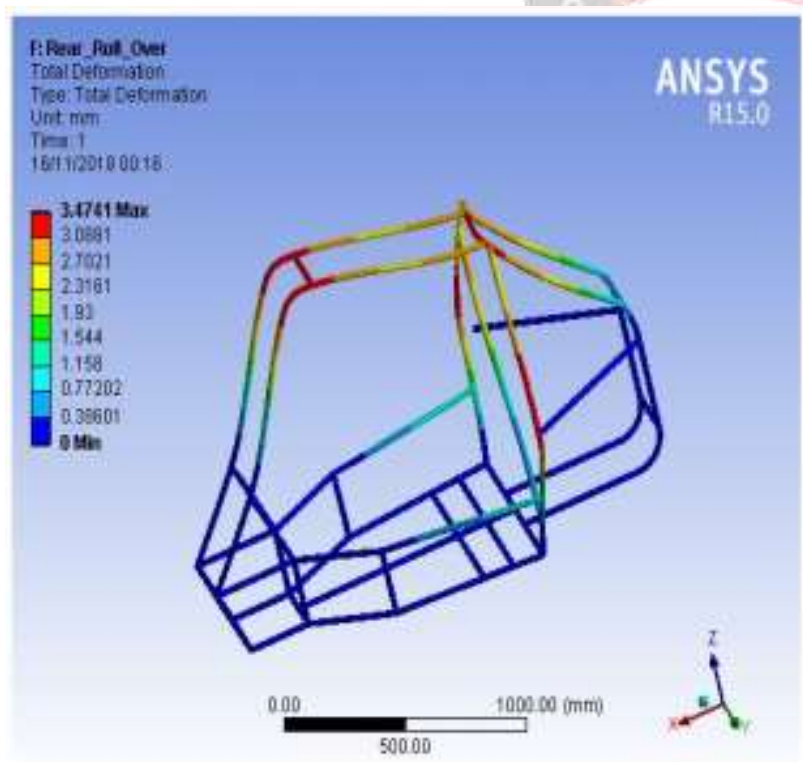

Figure 10: Total Deformation in Rear rollover

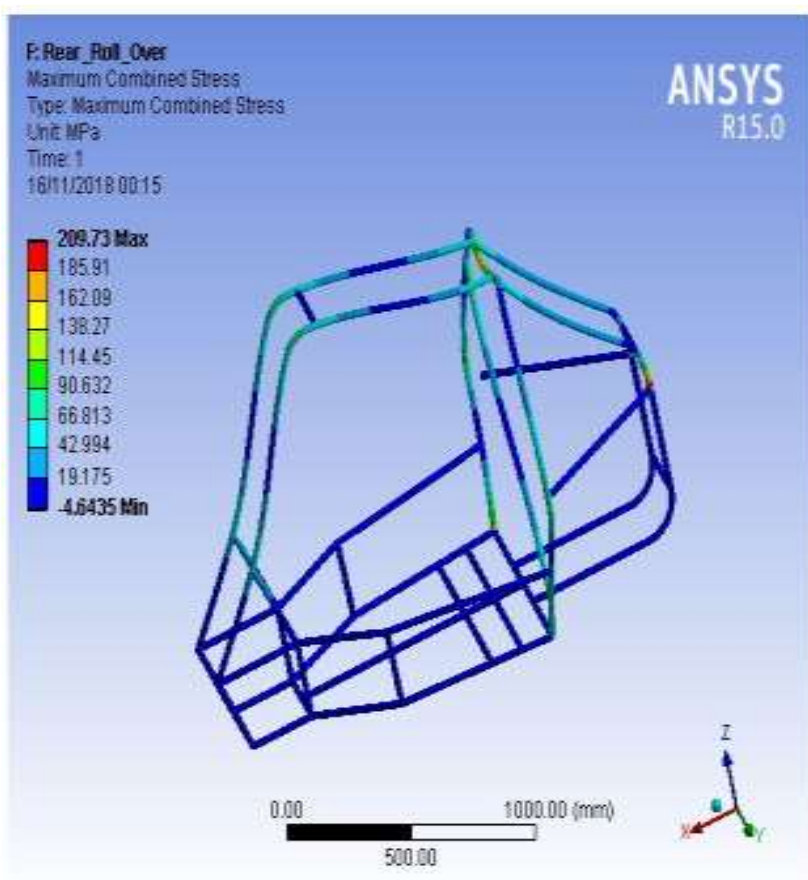

Figure 11: Max. Stress in Rear rollover

\section{The factor of Safety (FOS)}

The factor of the safety of roll cage should be greater than 1.5. Rear rollover analysis maximum stress obtained is 209.73 MPa. So FOS can be calculated as follows.

FOS $=$ Maximum stress/ Allowable stress

$$
\begin{aligned}
& =460 / 209.73 \\
& =2.19
\end{aligned}
$$

Here FOS obtained for rear roll over is 2.19 which is greater than 1.5 . So we can conclude that our design is safe in rear rollover analysis.

\section{CONCLUSION}

We have successfully analyzed the roll cage structure in ANSYS 15.0. The factor of safety for all the cases is in the safe limit, so we can conclude that our design is safe in front, rear and side impact analysis and also in front and rear rollover analysis. Stresses obtained are below yield stresses and also under safe range for the pipes used. The thickness of the pipe is above required thickness as mentioned in BAJA SAE Rulebook [1]. Material Characteristics are suitable for our design as FOS is above 1.5 in every case. AISI 4130 (Chromoly) is also having more corrosion resistance and high strength to weight ratio. So from all the obtained results, we can say that our design is having optimum FOS. This makes the roll cage safe for driver and thus the fabrication can be started. The results obtained from the analysis are summarized in the following table: 


\begin{tabular}{|l|c|c|c|}
\hline \multicolumn{1}{|c|}{ Type } & Stress & $\begin{array}{c}\text { Deformation } \\
\mathrm{mm}\end{array}$ & FOS \\
\hline Front & 276.47 & 0.70 & 1.66 \\
\hline Rear & 202.66 & 0.85 & 2.26 \\
\hline Side & 215.54 & 6.14 & 2.13 \\
\hline $\begin{array}{l}\text { Front Roll } \\
\text { Over }\end{array}$ & 165.41 & 2.60 & 2.78 \\
\hline $\begin{array}{l}\text { Rear Roll } \\
\text { Over }\end{array}$ & 209.73 & 3.47 & 2.19 \\
\hline
\end{tabular}

Table 3: Results

Thus the results shown in the above table proves that the vehicle roll cage designed is safe. While studying all the impacts on the roll cage the factor of safety was found to be more than 1.5 .

\section{REFERENCES}

[1] Koppenwallner et Alt., Analysis of ATV Destructive ReEntry Including Explosion Events, 2005, 4 European Conference on Space Debris, 18-20 April 2005, ESOC, Darmstadt, Germany.

[2] Aru, S., Jadhav, P., Jadhav, V and Angane, P. 'Design Analysis and Optimization of a Multi Tubular Space Frame', International Journal of Mechanical and Production Engineering Research and Development (IJMPERD) ISSN(P): 2249-6890; ISSN(E): 2249-8001 Vol. 4, Issue 4, Aug 2014, 37-48@ TJPRC Pvt. Ltd.

[3] Deepak Raina, Rahul Dev Gupta, Rakesh Kumar Phanden. 'Design and Development for Roll Cage of All-Terrain Vehicle' International Journal For Technological Research In Engineering (IJTRE) Volume 2, Issue 7, March-2015 ISSN: 2347-4718.

[4] Siddahant Jain, Palash Goyal, Rahul Dabi. 'Modelling and Finite Element Analysis of ATV', International Research Journal of Engineering and Technology (IRJET) e-ISSN: 2395-0056 p-ISSN: 2395-0072 Volume: 05 Issue: 02 | Feb2018.

[5] D. Nagarjuna, Junaid Mohammed Farooq, A. S. N. Saiteja, P. Siddhartha Sri Teja,"Optimization of Chassis of an All Terrain Vehicle" (2013), International Journal of Innovative Technology and Exploring Engineering (IJITEE), Volume-2, Issue-2, January 2013, pp.55-57.

[6] Sandeep Garg, Ravi Shankar Raman, "Design Analysis Of The Roll Cage For All - Terrain Vehicle" (2013), International Journal of Research in Engineering And Technology, Volume: 02 Issue: 09, Sep-2013, pp. 333-338

[7] Deepak Raina, Rahul Dev Gupta, Rakesh Kumar Phanden, "Design and Development For Roll Cage of All-Terrain Vehicle" (2015), International Journal For Technological Research In Engineering (IJTRE) Volume 2, Issue 7, March2015, pp. 1092-1099.

[8] Upendra S. Gupta, Sumit Chandak, Devashish Dixit, "Design \& Manufacturing of All Terrain Vehicle (ATV)- Selection, Modification, Static \& Dynamic Analysis of ATV Vehicle"

(2015), International Journal of Engineering Trends and Technology (IJETT) - Volume 20 Number 3 - Feb 2015, pp. 131-138.

[9] Shaik khajamoinuddin, B.Balaji, "Modal and Static Analysis of a Standard All-Terrain Vehicle Chassis" (2014), International Journal of Engineering Development and Research, Volume 2, Issue 1, pp. 479-483.

[10] Amrit Om Nayak, S. Kalaivanan, D. Manikandan, G. Ramkumar, T. Manoj, M. A.Kannan, "Complete Design and Finite Element Analysis of an all Terrain Vehicle", International Journal of Mechanical and Industrial Engineering (IJMIE), Volume-1, Issue-3, 2012, pp. 85-95.

[11] Aniket Thosar, "Design, Analysis and Fabrication of Rear Suspension System for an All Terrain Vehicle", International Journal of Scientific \& Engineering Research, Volume 5, Issue 11, November-2014, pp. 258-263

[12] Denish S. Mevawala, Mahesh P. Sharma, Devendra A. Patel, Darshan A. Kapadia, "Stress Analysis of Roll Cage for an All Terrain Vehicle", IOSR Journal of Mechanical and Civil Engineering (IOSR-JMCE), p-ISSN: 2320-334X, PP 49-53.

[13] A.V.S.Abhinav, "Simulation of Roll cage of an All-Terrain Vehicle considering inertia, using Transient Multi-body analysis", IOSR Journal of Mechanical and Civil Engineering, Volume 11,Issue 5 Ver. III (Sep- Oct. 2014), PP 23-26.

[14] Kasi Kamalakkannan, A. Elayaperumal, Sathyaprasad Managlaramam, "Simulation Aspects of a Full-Car ATV Model Semi-Active Suspension", scientific research, Engineering,2012, 4,pp. 384-389. 